\title{
PENGARUH CAPITAL ADEQUACY RASIO, DANA PIHAK KETIGA, DAN NON PERFORMING LOAN, TERHADAP PROFITABILITAS DENGAN LDR SEBAGAI VARIABEL INTERVENING PADA BANK UMUM KONVENSIONAL DI INDONESIA
}

\author{
Ivan Lisfi Alphamalana \\ Universitas Negeri Surabaya \\ ivanlisfi8@gmail.com \\ RA Sista Paramita \\ Universitas Negeri Surabaya \\ sistaparamita@unesa.ac.id
}

\begin{abstract}
The Bank is an institution that has a role as a financial intermediary between parties who need funds and can facilitate the payment flows. Additionally, The Bank has a function as industries that rely on public trust, so the health level of the Bank needs to be maintained. Profitability is essential for a bank because it measures a company's effectiveness in generating profits by maximizing its assets. This research aim is to investigate the effect of Capital Adequacy Ratio (CAR), Third Parties Funds (TPF), dan Non-Performing Loan (NPL), on Profitability with LDR as Intervening Variables. This research population is conventional commercial banks in Indonesia between 2012 to 2016. This research type is causality research using quantitative data-the sampling technique using a purposive sampling total of 150 samples. The statistical analysis tool in this research is lane analysis with software versions of AMOS 22 and IBM SPSS. The conclusion from this research results that $C A R, T A P I F$, and NPL variables affect LDR. The CAR, TPF, and LDR variables have not affected profitability, while the NPL variable affects profitability. Furthermore, CAR, TPF, and NPL cannot mediated by LDR.
\end{abstract}

Keywords: Capital Adequacy Ratio (CAR); Loan to Deposit Ratio (LDR); Non-Performing Loans (NPL); Profitability; Third-Party Funds (TPF).

\section{PENDAHULUAN}

Bank berperan sebagai penghubung keuangan pihak surplus dengan pihak deficit dan memperlancar peredaran arus pembayaran. Oleh karena itu, perbankan perlu menjaga kesehatan kinerjanya terutama profitabilitasnya agar dapat menyalurkan dividen, mengembangkan kegiatan usahanya, dan mampu mendapat isyarat prudential banking (Wijaya \& Sihombing, 2012). Dalam menciptakan dan memelihara perbankan yang sehat diperlukan lembaga perbankan yang perkembangannya terdapat pembinaan dan pengawasan yang efektif karena pada dasarnya kesehatan bank merupakan cerminan dari kondisi bank saat ini dan di waktu yang akan datang. Maka dari itu, sehat tidaknya perbankan dapat dilihat melalui profitabilitas bank itu sendiri karena tujuan utama perbankan adalah mencapai profitabilitas yang maksimal. Profitabilitas merupakan kemampuan bank dalam menghasilkan atau memperoleh laba secara efektif dan efisien. Laba yang diperoleh perusahaan berasal dari penjualan dan pendapatan investasi yang dilakukan oleh perusahaan. Intinya adalah profitabilitas menunjukkan efisiensi perusahaan (Kasmir, 2014).

Perbankan harus dilakukan evaluasi secara terus-menerus, karena krisis keuangan global pada tahun 2008 telah mengubah pola pikir optimis sebelumnya dari para pengamat ekonomi. Tekanan likuiditas global telah menyebabkan arus keluar modal portofolio jangka pendek besar-besaran diikuti dengan penurunan kinerja pasar keuangan Indonesia. Pada krisis keuangan global tahun 2008 yang berdampak pada kinerja perbankan membuat tingkat likuiditas global meningkatkan arus keluar modal portofolio jangka pendek diiringi kinerja pasar keuangan Indonesia yang menurun. Dalam menjaga tingkat keseimbangan perekonomian pada masa krisis tahun 2008, BI rate di bank Indonesia perlahan dinaikkan berawal dari 8,0\% pada April 2008 menjadi 9,5\% pada Oktober 2008. Kondisi ini menunjukkan semakin ketatnya persaingan likuiditas perbankan yang berlomba meningkatkan suku bunga agar masyarakat tertarik untuk bertransaksi di bank tersebut (Masdupi \& Defri, 2012). CAR 
Ivan Lisfi Alphamalana \& RA Sista Paramita. Pengaruh Capital Adequacy Rasio, Dana Pihak Ketiga, dan Non Performing Loan, terhadap Profitabilitas dengan LDR sebagai Variabel Intervening pada

Bank Umum Konvensional di Indonesia

pada perbankan Indonesia per Desember 1996 hanya sebesar 11,8\% kemudian dibandingkan dengan CAR pada Desember 2007 yang nilainya sebesar 19,3\% dan aturan serta pengawasan oleh Bank Indonesia tahun 2008 yang lebih ketat dari tahun 1997 (Rivai, 2007). Awalnya CAR ditetapkan 8\% minimal dalam Peraturan Bank Indonesia Nomor 10/15/PBI/2008, ketentuan CAR 8\% dalam Peraturan Bank Indonesia berlaku sejak 31 Desember 2001 dan berlaku sampai saat penelitian ini dilakukan. Berikut ini yaitu data ROA bank konvensional dan bank syariah periode 2012-2016.

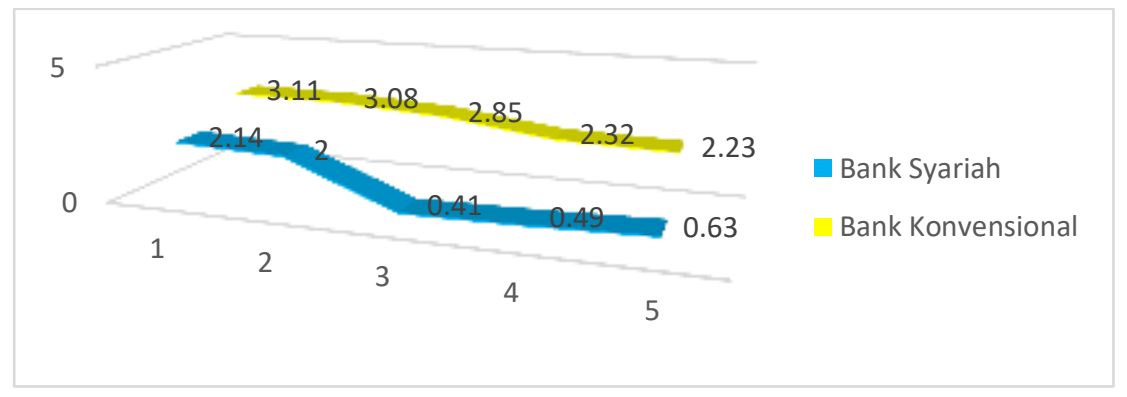

Sumber: Otoritas Jasa Keuangan (2016), data diolah

Gambar 1. PERTUMBUHAN ROA

Gambar 1 menunjukkan rata-rata perkembangan ROA bank konvensional dan ROA bank Syariah tahun 2012-2016 sebesar 2,72\% dan 1,13\%. ROA sebagai proksi kinerja perbankan yang mencerminkan efektivitas operasional bank untuk menghasilkan laba dengan mengoptimalkan aset lancar (Pardede \& Pangestuti, 2016). ROA bank konvensional yang lebih tinggi menjadi alasan untuk dipilih menjadi sampel.

Faktor-faktor yang memengaruhi profitabilitas diantaranya yaitu CAR, NPL, dan DPK serta LDR (Wityasari\& Pangestuti, 2014); (Ayuningrum \& Widyarti, 2009);(Fadjar, et. al, 2013);(Yanuardi, et. al2014). Oleh karena itu, penelitian ini diberi judul "Pengaruh Capital Adequacy Ratio, Dana Pihak Ketiga, dan Non Performing Loan, terhadap Profitabilitas dengan LDR sebagai Variabel Intervening pada Bank Umum Konvensional di Indonesia Periode 2012-2016". Tujuan penelitian ini adalah untuk menguji secara empiris apakah CAR, DPK, dan NPL memiliki pengaruh terhadap LDR dan profitabilitas pada bank umum konvensional di Indonesia periode 2012-2016.

\section{KAJIAN PUSTAKA DAN PENGEMBANGAN HIPOTESIS}

\section{Profitabilitas}

Menurut Dewi, Arifati, \& Andini (2016), profitabilitas adalah cara bank untuk mendapatkan keuntungan (profit) dalam penjualan, aset, dan modal saham tertentu. Profitabilitas yaitu upaya bank dalam menciptakan laba (profit) yang menjadi dasar pembagian dividen perusahaan (Putrama, 2017).

Analisis profitabilitas dipakai sebagai tolak ukur manajemen bank untuk mendapatkan keuntungan secara menyeluruh, sehingga setiap badan usaha terus melakukan evaluasi dan meningkatkan profitabilitasnya dengan berbagai upaya, karena jika tingkat profitabilitas bank semakin tinggi maka kinerja bank tersebut lebih tertata (Adityantoro \& Rahardjo, 2013).

\section{Capital Adequacy Rasio}

CAR merupakan rasio antara modal sendiri dibagi dengan Aktiva Tertimbang Menurut Risiko (ATMR) (Wibowo \& Syaichu, 2013). Aset lancar bank yang beresiko (kredit, penyertaan, surat berharga, tagihan pada bank lain) akan ditunjukkan oleh CAR (Haritsman \& Usman, 2017).Bank harus mencukupi kebutuhan modal minimum, karena modal penting agar bank dapat menyalurkan kredit kemasyarakat (Wityasari \&Pangestuti, 2014).

Wityasari \& Pangestuti (2014), Ayuningrum \& Widyarti (2009),Nadi (2017)Aini (2013),Nisar, et.al,(2015), Haryanto (2016), Yanuardi et.al. (2014) menyatakan bahwa CAR memiliki pengaruh 
positif terhadap profitabilitas. Temuan berbeda ditunjukkan oleh Aulia \& Prasetiono (2016) dan Jha \& Hui (2012), yang menjelaskan bahwa CAR memiliki pengaruh negatif terhadap profitabilitas. Selain itu Gul, et.al, (2011), Ariyanti, et.al (2017), Ebenezeret al. (2017),Shidieq (2015), Fadjar et. al. (2013),dan Masood \& Ashra (2012) menjelaskan bahwa CAR tidak berpengaruh pada profitabilitas.

\section{Dana Pihak Ketiga}

DPK yaitu dana yang disimpan oleh masyarakat. Bank memaksimalkan dana tersebut untuk disalurkan dalam bentuk kredit dengan porsi lebih besar dibandingkan dengan dana dari simpanan masyarakat untuk menunjang penghasilan perbankan dengan memaksimalkan dana tersebut berupa kredit (Hasan, et.al, 2014).

DPK berpengaruh positif terhadap profitabilitas berdasarkan penelitian Wityasari \& Pangestuti (2014), Kolapo, et.al,(2016) dan Gul et al. (2011). Berbeda dengan penelitian Masood \& Ashra (2012), DPK berpengaruh negatif terhadap Profitabilitas. Temuan lain dari Pardede \& Pangestuti (2016), Ariyanti et al. (2017)danPermatasari \& Amboningtyas (2017) yang menggambarkan bahwa DPK tidak memiliki pengaruh terhadap Profitabilitas.

\section{Non-Performing Loan}

NPL merupakan salah satu risiko keuangan yang menggambarkan resiko kredit. NPL merupakan pinjaman yang menemui kesulitan pada saat melunasi pinjaman atau sering disebut kredit bermasalah pada bank. (Agustiningrum, 2013). Menurut Defri (2012), jika Non Performing Loan dikelola dengan tidak benar akan menyebabkan hilangnya peluang untuk mendapatkan pendapatan dari kredit, sehingga keuntungan yang didapat akan berkurang.

NPL berpengaruh negatif terhadap profitabilitas, seperti temuan Wityasari \& Pangestuti (2014), Choerudin, et.al,(2016), Ayuningrum \& Widyarti (2009), Nadi (2017), Septiani \& Lestari (2016),Nisar et al.(2015), Fadjar et al. (2013). Selain itu, berbeda dengan temuan Aini (2013), Permatasari \& Amboningtyas (2017) dan Jha \& Hui (2012) menjelaskan bahwa NPL tidak memiliki pengaruh terhadap profitabilitas, sedangkan Yanuardi, et al. (2014) menemukan bahwa NPL memiliki pengaruh positif terhadap profitabilitas.

\section{Loan to Deposit Rasio}

LDR diartikan untuk menguji total jumlah kredit yang disalurkan kemudian dibandingkan dengan jumlah dana yang dihimpun dari masyarakat maupun dari jumlah modal sendiri (Kasmir, 2014:315). LDR berpengaruh positif terhadap profitabilitas seperti temuan Sudiyatno \& Suroso (2010), Pardede \& Pangestuti (2016), Choerudin et al. (2016)dan Shidieq (2015). Hal ini berbeda dengan Fadjar et al.(2013)dan Agustiningrum (2013) yang menjelaskan bahwa LDR memiliki pengaruh negatif terhadap profitabilitas. Selain itu, Wityasari \& Pangestuti (2014),Aini (2013),Septiani \& Lestari (2016) dan Permatasari \& Amboningtyas (2017) menjelaskan bahwa LDR tidak memiliki pengaruh terhadap profitabilitas.

\section{Hubungan antar Variabel}

Tingkat kecukupan modal sangat penting bagi bank untuk menyalurkan kreditnya. Apabila tingkat kecukupan modal bank baik, maka masyarakat tertarik untuk mengambil kredit, dan pihak bank akan cukup mempunyai dana cadangan bila sewaktu-waktu terjadi kredit macet (Wityasari \& Pangestuti, 2014). Menurut Pratiwi \& Wiagustini (2015), bank yang memiliki CAR yang tinggi maka kredit nya juga banyak, sehingga apabila CAR meningkat maka akan meningkatkan LDR.

H1: CAR berpengaruh terhadap LDR. 
Ivan Lisfi Alphamalana \& RA Sista Paramita. Pengaruh Capital Adequacy Rasio, Dana Pihak Ketiga, dan Non Performing Loan, terhadap Profitabilitas dengan LDR sebagai Variabel Intervening pada

Bank Umum Konvensional di Indonesia

Dana pihak ketiga merupakan dana berupa simpanan dari masyarakat. Bank dapat menyalurkan kredit lebih banyak dengan menggunakan dana yang besar dari masyarakat untuk dapat memanfaatkan dana tersebut untuk ditempatkan pada pos-pos yang menghasilkan pendapatan bagi bank, salah satunya yaitu dalam bentuk kredit (Hasan, et. all, 2014). Jika dana pihak ketiga meningkat maka akan mengakibatkan pertumbuhan kredit, oleh karena itu pertumbuhan DPK berpengaruh terhadap LDR (Pardede \& Pangestuti, 2016).

H2: DPK berpengaruh terhadap LDR.

Menurut Defri (2012), jika NPL apabila tidak dapat ditangani dengan tepat, maka akan terjadi diantaranya kesempatan memperoleh kesempatan pendapatan (income) dari kredit yang diberikan akan hilang, sehingga laba berkurang dan kemampuan untuk memberikan kredit berkurang. Kredit bermasalah semakin meningkat sehingga membuat bank tidak berani meningkatkan penyaluran kreditnya apalagi bila dana pihak ketiga tidak dapat dicapai secara optimal maka likuiditas suatu bank akan terganggu, oleh karena itu kredit bermasalah berpengaruh terhadap LDR.

H3: NPL berpengaruh terhadap LDR.

Semakin tinggi CAR maka semakin baik kemampuan bank tersebut untuk menanggung risiko dari setiap kredit/aktiva produktif yang berisiko. Selain itu jika nilai CAR tinggi maka bank tersebut mampu membiayai kegiatan operasional dan memberikan kontribusi yang cukup besar bagi profitabilitas CAR memiliki pengaruh terhadap profitabilitas (Pardede \& Pangestuti, 2016).

H4: CAR berpengaruh terhadap profitabilitas.

Bank bertugas memberikan pelayanan kepada masyarakat, bank harus selalu berada di tengah masyarakat agar arus uang dari masyarakat yang kelebihan dana dapat disalurkan kepada pihak yang kekurangan dana. Meningkatnya kapasitas kredit menyebabkan perolehan pendapatan meningkat sehingga laba yang diperoleh bank juga meningkat dan ini yang menjadikan dana pihak ketiga berpengaruh terhadap profitabilitas (Pardede \& Pangestuti, 2016).

H5: DPK berpengaruh terhadap profitabilitas.

Kredit bermasalah adalah suatu kondisi dimana pada saat itu pihak peminjam tidak dapat memenuhi kewajibannya pada saat jatuh tempo yang mengakibatkan semakin tinggi kredit macet suatu bank, maka hal tersebut akan mengganggu kinerja bank tersebut (Pranata, 2015). Semakin tinggi kredit macet maka akan semakin buruk kualitas kredit bank yang menyebabkan jumlah kredit bermasalah semakin besar, dan oleh karena itu bank harus menanggung kerugian dalam kegiatan operasionalnya sehingga berpengaruh terhadap penurunan laba bank (Kasmir, 2014:113).

H6: NPL berpengaruh terhadap profitabilitas.

Semakin tinggi nilai rasio LDR menunjukkan semakin rendahnya kemampuan likuiditas bank yang bersangkutan sehingga kemungkinan suatu bank dalam kondisi bermasalah akan semakin besar (Ayuningrum \& Widyarti, 2009).

H7: LDR berpengaruh terhadap profitabilitas.

Bank yang memiliki CAR yang tinggi maka kredit nya juga banyak maka menunjukkan kemampuan bank dalam mengelola risikonya semakin kuat dan bagus, sehingga apabila CAR meningkat maka akan meningkatkan LDR (Pardede \& Pangestuti, 2016). Semakin rendah LDR menunjukkan kurangnya efektifitas bank dalam menyalurkan kredit sehingga bank kehilangan kesempatan untuk memperoleh laba (ROA) (Purnamasari \& Jumono, 2013). 
H8: CAR berpengaruh signifikan terhadap Profitabilitas melalui mediasi LDR.

LDR mencerminkan kemampuan bank dalam membayar kembali penarikan dana yang dilakukan deposan dengan mengandalkan kredit yang diberikan sebagai sumber likuiditasnya. Semakin tinggi nilai rasio LDR menunjukkan semakin rendahnya kemampuan likuiditas bank yang bersangkutan sehingga kemungkinan suatu bank dalam kondisi bermasalah akan semakin besar (Ayuningrum \& Widyarti, 2009).

H9: DPK berpengaruh signifikan terhadap Profitabilitas melalui mediasi LDR.

Salah satu risiko yang dihadapi bank dalam menyalurkan kredit adalah tidak terbayarnya kredit yang telah diberikan atau biasa disebut risiko kredit, semakin tinggi kredit macet suatu bank maka hal tersebut akan mengganggu kinerja bank tersebut. (Defri, 2012).

H10: NPL berpengaruh signifikan terhadap Profitabilitas melalui mediasi LDR.

Hubungan antar variabel secara keseluruhan digambarkan di Gambar 2.

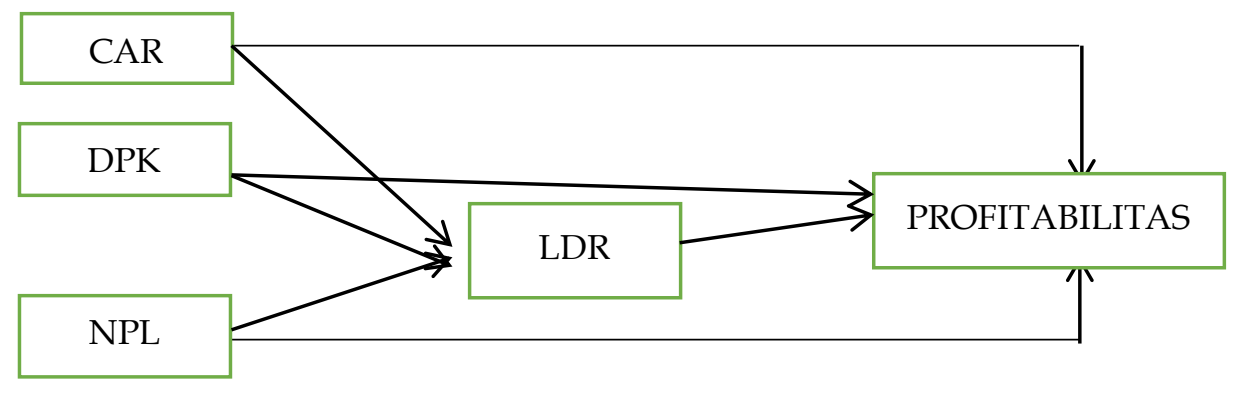

\section{Gambar 2. MODEL PENELITIAN}

\section{METODE PENELITIAN}

Jenis penelitian ini yaitu penelitian konklusif dengan pendekatan kausalitas. Populasi yang digunakan yaitu data perbankan di Indonesia periode 2012-2016. Metode penentuan sampel memakai metode purposive sampling dengan menggunakan data yang dianalisis secara kuantitatif, dengan kriteriakriteria sebagai berikut: Bank umum konvensional di Indonesia dan Laporan keuangan bank di publikasi secara lengkap selama periode 2012-2016. Ukuran sampel yang ditetapkan sebanyak 30 bank. Teknik Analisis dalam penelitian ini adalah analisis jalur (path analysis) yang mana pengukurannya menggunakan program AMOS 22.0 (Analysis of Moment Structure) dan IBM SPSS Statistics 22.0.

\section{HASIL DAN PEMBAHASAN}

\section{Hasil Uji Statistik}

Penelitian ini menggunakan data sekunder dan teknik pengambilan data dengan cara studi kepustakaan dan dokumentasi. Tabel 1 menunjukkan hasil asumsi normalitas didapatkan nilai critical ratio kurtosis value secara multivariate sebesar -1.120 yang mana nilai tersebut antara rentang $-2,58$ sampai $+2,58$. Bisa diartikan bahwa asumsi multivariate normality sudah dilengkapi dan data dinyatakan layak untuk digunakan.

Pengujian outlier dapat dilihat dari output pada mahalanobis distance. Syarat yang dipakai dalam uji outlier yaitu berdasarkan nilai Chi-Square pada derajat kebebasan (degree of freedom) 5 adalah jumlah variabel dengan tingkat signifikansi 0.01 maka diperoleh nilai mahalonobis distance sebesar $\mathrm{X}^{2}(5,0.01)=15,086$. Hasil tersebut menandakan semua kasus yang memiliki nilai Mahalanobis $d$ squared lebih tinggi dari 15,086 adalah multivariate outlier. Berdasarkan hasil uji outlier 
Ivan Lisfi Alphamalana \& RA Sista Paramita. Pengaruh Capital Adequacy Rasio, Dana Pihak Ketiga, dan Non Performing Loan, terhadap Profitabilitas dengan LDR sebagai Variabel Intervening pada

Bank Umum Konvensional di Indonesia

menunjukkan bahwa tidak ditemukan nilai yang dianggap sebagai multivariate outliers karena data pada mahalanobis distance tidak ada yang melampaui 15,086. Sehingga data yang digunakan layak untuk dilanjutkan dalam estimasi selanjutnya.

Tabel 1.

HASIL UJI NORMALITAS

\begin{tabular}{lrrrrrr}
\hline Variabel & Min & Max & Skew & c.r. & Kurtosis & c.r. \\
\hline Sqrtnpl &, 458 & 3,154 &, 209 &, 979 &, 923 & 2,155 \\
Dpk & 72,150 & 98,950 &,- 470 & $-2,196$ &,- 541 & $-1,265$ \\
Sqrtcar & 3,231 & 5,283 &, 275 & 1,283 &, 160 &, 373 \\
Ldr & 55,340 & 110,450 &,- 721 & $-3,367$ & 1,084 & 2,532 \\
sqrtroa1 & 1,044 & 2,480 &, 344 & 1,609 &,- 137 &,- 320 \\
multivariate & & & & & 1,638 & 1,120 \\
\hline
\end{tabular}

Sumber: Hasil olah data (2020)

Tabel 2 menunjukkan nilai squared multiple correlations variabel LDR adalah $0.202\left(\mathrm{R}^{2}\right)$ yang berarti bahwa variabel LDR dipengaruhi variabel SqrtCAR, DPK dan SqrtNPL sebesar 20,2\%, sedangkan $79,8 \%$ dijelaskan pada variabel lain yang tidak diteliti. Nilai squared multiple correlations untuk variabel Profitabilitas sebesar $0.278\left(\mathrm{R}^{2}\right)$ yang berarti variabel Profitabilitas dipengaruhi oleh variabel SqrtCAR, DPK dan SqrtNPL dan LDR sebesar 27,8\%. Sedangkan, 72,2\% dijelaskan variabel lain yang tidak diteliti.

Tabel 2.

HASIL UJI KOEFISIEN DETERMINASI

\begin{tabular}{cc}
\hline Variabel & Estimate \\
\hline Loan Deposit Ratio & 0,202 \\
Profitabilitas & 0,278 \\
\hline
\end{tabular}

Sumber: Data diolah (2020)

\section{Hasil Uji Analisis Jalur}

Model dalam Gambar 3 dikonversi dalam persamaan model struktural. Penghitungan nilai e1 dan e2 dapat dilihat di persamaan (1) dan (2) (Sarwono, 2012:15). Sedangkan, persamaan model struktural dalam penelitian ini dapat dilihat di persamaan (3) dan (4).

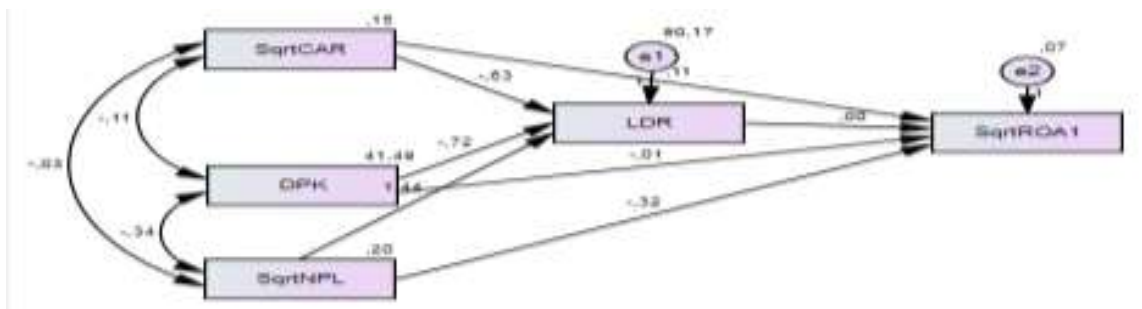

Sumber: Data diolah (2020)

Gambar 3. MODEL DIAGRAM JALUR

$\mathrm{e} 1=\sqrt{1-R 1^{2}}=\sqrt{1-0.202}=0.893$

$\mathrm{e} 2=\sqrt{1-R 2^{2}}=\sqrt{1-0.278}=0.850$

$\mathrm{Z}=-0,626 \mathrm{X} 1+(-0.723 \mathrm{X} 2)+1,441 \mathrm{X} 3+0.893$

$Y=0.106 X 1+(-0.010 X 2)+(-0324 X 3)+0.003 Z+0.850$ 
Tabel 3.

HASIL UJI HIPOTESIS

\begin{tabular}{lllrrrc}
\hline \multicolumn{2}{l}{ Hubungan antar Variabel } & Estimate & \multicolumn{1}{c}{ S.E. } & \multicolumn{1}{c}{ C.R. } & \multicolumn{1}{c}{ P } \\
\hline LDR & $\leftarrow$ & SqrtCAR &,- 626 & 2,155 &,- 290 &, 772 \\
LDR & $\leftarrow$ & DPK &,- 723 &, 131 & $-5,537$ & $* * *$ \\
LDR & $\leftarrow$ & SqrtNPL & 1,441 & 1,914 &, 753 &, 452 \\
SqrtROA1 & $\leftarrow$ & SqrtCAR &, 106 &, 062 & 1,726 &, 084 \\
SqrtROA1 & $\leftarrow$ & DPK &,- 010 &, 004 & $-2,422$ &, 015 \\
SqrtROA1 & $\leftarrow$ & SqrtNPL &,- 324 &, 055 & $-5,921$ & $* * *$ \\
SqrtROA1 & $\leftarrow$ & LDR &, 003 &, 003 & 1,090 &, 276 \\
\hline
\end{tabular}

Sumber :Data diolah (2020)

Dalam uji hipotesis menunjukkan bahwa setiap variabel independen $(X)$ yaitu SqrtCAR, DPK, dan SqrtNPL terhadap variabel mediasi (Z) yaitu LDR menunjukkan nilai critical ratio di bawah 2.00. Hal tersebut berarti koefisien jalur adalah signifikan. Sedangkan, masing-masing variabel independen (X) yaitu SqrtCAR, DPK, dan SqrtNPL dan variabel mediasi (Z) yaitu LDR, tidak berpengaruh signifikan terhadap variabel dependen (Y) yaitu Profitabilitas karena nilai critical ratio berada di bawah 2.00 .

\section{Hasil Uji Mediasi}

Berdasarkan hasil uji tabel 2, mediasi terbukti secara parsial. Hal ini terbukti bahwa variabel CAR (X1), DPK (X2), dan NPL (X3) memiliki pengaruh signifikan terhadap Profitabilitas (Y) secara langsung, sedangkan variabel CAR (X1), DPK (X2), dan NPL (X3) tidak berpengaruh secara signifikan terhadap Profitabilitas (Y) secara tidak langsung dan harus melalui variabel LDR (Z) sebagai variabel intervening. Ini menunjukkan bahwa menambahkan LDR (Z) sebagai variabel intervening memiliki pengaruh signifikan. Dengan demikian, hasil dalam penelitian ini mediasi terbukti secara persial (partially mediating).

\section{Pengaruh Capital Adequacy Ratio terhadap Loan Deposit Ratio}

CAR memiliki pegaruh negatif terhadap LDR ditinjau dari kegunaan modal bank yaitu untuk melengkapi kelengkapan modal minimum. jika bank memiliki nilai CAR yang tinggi maka kreditnya juga tinggi kemudian jika CAR meningkat maka LDR akan meningkat. Dalam penelitian ini pihak bank dalam masalah kinerja kurang maksimal dalam melakukan usaha untuk memberikan kredit ke masyarakat semisal promosi dan sebagainya sehingga menyebabkan bank sulit untuk memberikan kredit ke masyarakat. Dari penelitian ini juga bisa diperhatikan bahwa nilai LDR dari tahun ke tahun mengalami kenaikan sedangkan nilai CAR di perusahaan mengalami fluktuasi dan tidak ditunjang dengan mengeluarkan dana ke luar yang menyebabkan kerugian pada bank.

Hasil penelitian ini mendukung penelitian Jha \& Hui (2012), dan Aulia \& Prasetiono (2016) yang menjelaskan bahwa CAR berpengaruh negatif dan signifikan terhadap LDR. Berbeda dengan hasil penelitian yang dilakukan oleh Ayuningrum \& Widyarti (2009), Pardede \& Pangestuti (2016) dan Nadi, (2017) yang menjelaskan bahwa CAR berpengaruh positif terhadap LDR. Penelitian lain yang dilakukan oleh Ariyanti et al (2017), Shidieq (2015), Fadjar et al. (2013), (Masood \& Ashraf (2012), dan Gul et al. (2011) menjelaskan bahwa CAR tidak memiliki pengaruh pada LDR.

\section{Pengaruh Dana Pihak Ketiga terhadap Loan Deposit Ratio}

DPK memiliki pengaruh negatif terhadap LDR. Hal ini dapat dicermati dari nilai probabilitasnya. Pada hasil penelitian ini nilai probabilitas DPK terhadap LDR menjelaskan bahwa variabel Dana Pihak Ketiga memiliki pengaruh negatif dan kuat terhadap LDR (Z).

Struktur modal maksimal dapat dicapai saat keuntungan dan aktivitas dari hutang yang digunakan seimbang. Bank mampu menyalurkan kredit lebih banyak dengan menggunakan dana yang besar dari masyarakat kemudian dana mampu dikembalikan kemasyarakat untuk keperluan kredit. Apabila DPK meningkat maka pertumbuhan kredit akan meningkat. Namun ini tidak dimanfaatkan dengan baik 
Ivan Lisfi Alphamalana \& RA Sista Paramita. Pengaruh Capital Adequacy Rasio, Dana Pihak Ketiga, dan Non Performing Loan, terhadap Profitabilitas dengan LDR sebagai Variabel Intervening pada

Bank Umum Konvensional di Indonesia

oleh pihak bank. Hal ini dikarenakan minimnya upaya bank menarik masyarakat untuk percaya menaruh dananya berakibat pada DPK yang diperoleh bank tidak banyak. Dari penelitian ini juga menunjukkan adanya penurunan DPK sehingga berakibat pada sulitnya penyaluran kredit karena minim dana yang dimiliki.

Hasil penelitian ini mendukung penelitian Masood \& Ashraf (2012) yang menghasilkan pengaruh DPK negatif dan signifikan terhadap LDR. Berbeda dengan hasil penelitian yang dilakukan oleh Ariyanti et al. (2017), Pardede \& Pangestuti (2016), dan Permatasari \& Amboningtyas (2017) yang menjelaskan bahwa pengaruh DPK tidak signifikan terhadap LDR. Serta penelitian yang dilakukan oleh Wityasari \& Pangestuti (2014), Sudiyatno \& Suroso (2010), Kolapo et al., (2016), dan Gul et al., (2011) yang menghasilkan pengaruh DPK positif terhadap LDR.

\section{Pengaruh Non Performing Loan terhadap Loan Deposit Ratio}

NPL memiliki pengaruh positif terhadap LDR tetapi jika NPL tidak dapat diantisipasi dengan baik, maka kesempatan mendapatkan keuntungan dari kredit yang disalurkan akan hilang, sehingga keuntungan dan penyaluran kredit kembali kemasyarakat akan berkurang.dan jika dana yang dihimpun dari masyarakat tidak diraih secara maksimal maka tingkat likuiditas bank akan terhambat.

Pada penelitian ini bank menerapkan manajemen resiko yang bertujuan untuk mengatasi kredit macet dengan baik. Menurut Defri (2012) upaya yang dilakukan oleh bank yaitu dengan menyaring jaminan yang diberikan kreditur yang dapat dicairkan dengan cepat dengan cara lelang atau dijual sehingga bank mampu menyeimbangkan kredit macet untuk kelancaran operasional bank. Ketika kredit macet dapat kelola dengan baik oleh bank, maka bank dapat menyalurkan kembali dananya kepada masyarakat yang ingin mengajukan kredit

Hasil penelitian ini mendukung penelitian Yanuardi et al., (2014) yang menjelaskan bahwa NPL memiliki pengaruh positif terhadap LDR. Selain itu, hasil penelitian Aini (2013), Permatasari \& Amboningtyas (2017), Jha \& Hui (2012), dan Shidieq (2015) yang menjelaskan bahwa pengaruh NPL terhadap LDR tidak signifikan.

\section{Pengaruh Capital Adequacy Ratio terhadap Profitabilitas}

Penelitian ini melalui analisis jalur menjelaskan bahwa, CAR tidak signifikan terhadap Profitabilitas. Pada aset lancar, selain berpotensi mendapatkan keuntungan juga berpotensi menyebabkan resiko. Selanjutnya bank harus memaksimalkan modal agar tidak menyebabkan resiko kerugian pada aset lancar dan investasinya terutama dana yang telah dihimpun dari masyarakat. Peningkatan aset lancar adalah salah satu indikator rasio keuntungan yang didapatkan oleh bank dan dijadikan pertimbangan resiko untuk menjaga dana yang diinvestasikan oleh deposan.

Dalam penelitian ini, bank juga tidak terlalu bergantung pada CAR mengalami fluktuasi tetapi ROA atau Profitabilitas mengalami kenaikan dari tahun ketahun. Faktor lain yang mampu membantu pengoptimalan profitabilitas yakni memaksimalkan giro dari Bank Indonesia ataupun giro dari bankbank lain, tagihan ekseptasi, wesel tagih maupun efek-efek untuk tujuan investasi yang mampu membuat profitabilitas bank menjadi seimbang.

Dengan ini, CAR berpengaruh tidak signifikan terhadap Profitabilitas. Hasil penelitian ini mendukung penelitian penelitian Gul, et, al. (2011), Ariyanti, et, al. (2017), Ebenezer et al. (2017), Shidieq (2015), Fadjar et al. (2013), Masood \& Ashra (2012) dan Fadjar, et.al. (2013) yang menjelaskan bahwa CAR berpengaruh tidak signifikan terhadap Profitabilitas. Selain itu,penelitian yang dilakukan oleh Wityasari \& Pangestuti (2014), Ayuningrum \& Widyarti (2009), Nadi (2017), Aini (2013), Nisar et al. (2015), Haryanto (2016), Yanuardi et al. (2014) yang menjelaskan bahwa CAR berpengaruh positif terhadap Profitabilitas.

\section{Pengaruh Dana Pihak Ketiga terhadap Profitabilitas}


Penelitian ini menunjukkan bahwa DPK tidak berpengaruh terhadap Profitabilitas yang dinyatakan pada hasil uji koefisien jalur. DPK itu sendiri adalah ukuran kemampuan suatu bank dalam menangani biaya operasionalnya dari sumber dana simpanan masyarakat atau DPK. Ketika jumlah kredit yang menimbulkan jumlah pendapatan meningkat sehingga keuntungan yang diperoleh bank juga meningkat (Permatasari \& Amboningtyas, 2017). Pada penelitian ini DPK yang masuk ke bank jumlahnya mengalami fluktuasi setiap tahunnya maka bank memiliki opsi lain dari modal untuk mengoptimalkan kegiatan operasionalnya sehingga pengoptimalan profitabilitas tidak bergantung pada DPK.

Oleh karena itu, DPK tidak memiliki pengaruh terhadap Profitabilitas. Hasil ini didukung oleh Pardede \& Pangestuti (2016), Ariyanti et al. (2017) dan Permatasari \&Amboningtyas (2017) yang menjelaskan bahwa DPK berpengaruh tidak signifikan terhadap Profitabilitas. Selain itu, DPK mempunyai hubungan yang positif terhadap Profitabilitas seperti hasil penelitian dari Wityasari \& Pangestuti (2014), Kolapoet al.(2016) dan Gul et al. (2011). Hal ini berbeda dengan hasil penelitian dari Masood \& Ashraf (2012) yang menjelaskan bahwa DPK berpengaruh negatif terhadap terhadap Profitabilitas.

\section{Pengaruh Non Performing Loan terhadap Profitabilitas}

Penelitian ini menunjukkan NPL memiliki pengaruh negatif dan signifikan terhadap Profitabilitas. Penelitian ini memiliki hasil yang sesuai dengan Teori Manajemen resiko yang menggambarkan bahwa resiko kredit yaitu resiko yang terjadi karena kreditur tidak bisa membayarkan dana yang dipinjamkan dan bunga yang harus di bayar ketika sudah jatuh tempo. Bank harus mampu mengurangi rasio NPL karena rasio NPL berdampak buruk pada kinerja bank tersebut. Ketika nilai NPL menurun maka kredit macet akan menurun kemudian berdampak pada pendapatan bunga dari kredit akan meningkat, sehingga profitabilitas juga meningkat. Oleh karena itu NPL berpengaruh negatif dan signifikan terhadap profitabilitas.

Hasil penelitian ini didukung oleh Wityasari \& Pangestuti (2014), Choerudin, Yuniatun, \& Kusdiasmo (2016), Ayuningrum \& Widyarti (2009), Nadi (2017), Septiani \& Lestari (2016),Nisar et al.(2015), Fadjar et al. (2013) yang menjelaskan bahwa NPL memiliki hubungan negatif terhadap profitabilitas. Selain itu, penelitian dari Aini (2013), Permatasari \& Amboningtyas (2017) dan Jha \& Hui (2012) yang menjelaskan bahwa NPL tidak memiliki pengaruh terhadap profitabilitas. Selain itu berbeda pula dengan penelitian dari Yanuardi et al. (2014)yang menjelaskan bahwa NPL memiliki hubungan positif terhadap profitabilitas.

\section{Pengaruh Loan Deposit Ratio terhadap Profitabilitas}

Penelitian ini menunjukkan LDR (Z) memiliki pengaruh tidak signifikan terhadap Profitabilitas. LDR merupakan rasio yang memiliki pinjaman yang besar. Selain itu, LDR menggambarkan menggambarkan upaya bank dalam mengembalikan dana apabila sewaktu-waktu diambil oleh deposan dengan mengutamakan kredit yang disalurkan ke masyarakat sebagai sumber utamanya, atau sampai mana bank dapat menyalurkan kreditnya kepada nasabah dan kredit tersebut dapat menanggung kewajiban bank dalam memenuhi permintaan deposan yang akan mengambil kembali uangnya yang telah dimanfaatkan oleh bank untuk menyalurkan kredit yang disalurkan dengan total dana pihak ketiga.

Hal ini perlu dicermati lebih oleh pihak bank dalam kegiatan penyaluran kredit. Akan tetapi, penyaluran kredit yang cukup tanpa didukung dengan jaminan yang sesuai dengan kredit yang diberikan, atau dengan pemasukan dari masyarakat akan membuat bank dalam bahaya. Hal seperti ini pada umumnya yang dilakukan oleh bank yaitu dengan menjaga LDR agar tidak untuk terlalu besar mengeluarkan atau melakukan pembiayaan yang cukup besar yang akan berdampak bank akan kekurangan deposit. LDR yang cukup rendah juga rentan akan ketidakmampuan bank dalam menyalurkan kredit, ketika kredit sulit untuk disalurkan maka bank akan kesulitan dalam meningkatkan pendanaan kegiatan operasional bank. Data LDR dalam penelitian ini mengalami 
Ivan Lisfi Alphamalana \& RA Sista Paramita. Pengaruh Capital Adequacy Rasio, Dana Pihak Ketiga, dan Non Performing Loan, terhadap Profitabilitas dengan LDR sebagai Variabel Intervening pada Bank Umum Konvensional di Indonesia

fluktuasi tetapi tidak memengaruhi nilai ROA atau profitabilitas yang sedang dalam keadaan naik dari tahun ketahun. Hal ini dapat dilihat LDR tidak memiliki pengaruh signifikan terhadap Profitabilitas.

Hasil penelitian ini didukung oleh Wityasari \& Pangestuti (2014),Aini (2013),Septiani \& Lestari (2016) dan Permatasari \& Amboningtyas (2017) yang menjelaskan bahwa LDR tidak memiliki pengaruh terhadap profitabilitas. Sedangkan pada penelitian yang dilakukan oleh Sudiyatno \& Suroso (2010), Pardede \& Pangestuti (2016), Choerudin et al. (2016) dan Shidieq (2015) menjelaskan bahwa LDR berpengaruh positif terhadap profitabilitas.Selain itu, penelitian dari Fadjar et al.(2013) dan Agustiningrum (2013) yang menjelaskan bahwa LDR berpengaruh negatif terhadap profitabilitas.

\section{Pengaruh Capital Adequacy Ratio terhadap Profitabilitas melalui mediasi Loan to Deposit Ratio}

Berdasarkan pengujian Sobel Test terdapat hasil bahwa LDR berpengaruh yang negatif dalam memediasi pengaruh tidak langsung CAR terhadap Profitabilitas yang mana pengaruh secara tidak langsung nilainya lebih kecil dibandingkan dengan pengaruh secara langsung. Dengan demikian, dapat dicermati pada uji sobel test yang telah diuji bahwa nilai t masih kurang di bawah standard sehingga tidak mampu memediasi antar variabel independen (CAR) dengan variabel dependen (ROA). Selain itu, pembahasan sebelumnya dijelaskan bahwa LDR juga tidak berpengaruh terhadap profitabilitas maka dari itu rasio kecukupan modal tidak bisa memastikan bahwa Profitabilitas bank mampu menjadi acuan kredit yang diberikan kemasyarakat yang diukur dengan LDR.

LDR tidak mampu memediasi CAR terhadap profitabilitas disebabkan oleh penurunan ataupun peningkatan nilai CAR pada saat satu periode penelitian tidak mampu memengaruhi LDR. Nilai CAR yang meningkat akan membuat kemampuan permodalan bank juga akan meningkat. Ketika kemampuan permodalan bank meningkat akan menciptakan keuntungan bagi bank untuk mengantisipasi terjadinya kredit bermasalah atau resiko kegiatan bank yang lainnya. Jumlah CAR yang meningkat akan bisa menghalangi usaha suatu bank untuk melakukan pengembangan usaha seperti menyalurkan kredit, hal ini disebabkan bank dapat menampung jumlah modal yang besar sehingga bisa juga dimanfaatkan untuk menanggung apabila asetnya menurun sebagai bentuk antisipasi apabila terjadi kerugian untuk aset-aset bank yang beresiko. Oleh karena itu, hasilnya menggambarkan bahwa CAR tidak memiliki pengaruh signifikan terhadap ROA yang dimediasi oleh LDR. Hasil penelitian ini seperti penelitian dari (Wityasari \& Pangestuti, 2014) yang menyatakan bahwa tidak ada pengaruh CAR terhadap Profitabilitas yang dimediasi LDR.

\section{Pengaruh Dana Pihak Ketiga terhadap Profitabilitas melalui mediasi Loan to Deposit Ratio}

Berdasarkan pengujian Sobel Test memunculkan hasil bahwa LDR memiliki pengaruh yang negatif dalam memediasi pengaruh tidak langsung Dana Pihak Ketiga terhadap Profitabilitas yang mana pengaruh secara tidak langsung nilainya lebih kecil dibandingkan dengan pengaruh secara langsung. Dengan demikian, dapat dicermati pada uji sobel test yang sudah diteliti bahwa nilai t berada di bawah standard sehingga tidak mampu memediasi antar variabel independen (DPK) dengan variabel dependen (ROA). Selain itu juga bisa dicermati dari pembahasan sebelumnya kalau DPK juga tidak berpengaruh signifikan terhadap Profitabilitas dan LDR tidak mampu membuat pengaruh yang signifikan terhadap Profitabilitas.

Hal ini menggambarkan bahwa apabila nilai DPK yang didapatkan oleh bank tinggi belum sanggup untuk menilai kredit yang besar dapat disalurkan dengan lancar kemudian akan menunjukkan keuntungan yang diperoleh oleh bank tersebut. Semakin tinggi nilai DPK yg didapat akan tetapi tidak mampu didukung oleh kredit yang disalurkan dengan lancar maka bank tersebut kemungkinan akan terjadi kerugian profitabilitas karena kredit yang disalurkan kepada debitur dan juga pendapatan bunganya tidak mampu untuk menanggung resiko bunga yang harus dikembalikan kepada debitur. DPK tidak bisa memastikan Profitabilitas bank dengan faktor kredit yang telah diberikan. Ketika jumlah kredit yang diberikan tidak dapat juga memperngaruhi profitabilitas pada bank. Dengan demikian maka LDR tidak dapat memediasi pengaruh DPK terhadap Profitabilitas. Hasil penelitian ini seperti penelitian dari (Wityasari \& Pangestuti, 2014) yang menunjukkan bahwa tidak ada pengaruh DPK terhadap Profitabilitas yang dimediasi LDR. 
Pengaruh Non-Performing Loan terhadap Profitabilitas melalui mediasi Loan to Deposit Ratio Berdasarkan pengujian Sobel Test memunculkan hasil bahwa LDR tidak mampu memediasi pengaruh tidak langsung NPL terhadap Profitabilitas adapun pengaruh secara tidak langsung nilainya lebih kecil dibandingkan dengan pengaruh secara langsung. Hal tersebut dapat diperhatikan pada uji sobel test yang sudah diteliti bahwa nilai t berada di bawah standard sehingga tidak mampu memediasi antar variabel independen (NPL) dengan variabel dependen (ROA). LDR juga tidak memiliki pengaruh yang signifikan terhadap Profitabilitas yang dapat diperhatikan pada pengujian yang telah diteliti sebelumnya.

Dengan demikian hasil dari NPL dalam satu periode terakhir tidak mampu menjadikan acuan untuk jumlah kredit yang disalurkan kepada masyarakat yang diukur dengan LDR, kemudian LDR tersebut tidak dapat memastikan Profitabilitas pada bank. Selain itu, kondisi selalu adanya kredit macet bahkan setiap tahunnya mengalami peningkatan ini tidak akan dapat memengaruhi bank dalam melakukan penyaluran dana. Hal tersebut dikarenakan oleh pihak perbankan telah mengusahakan perlindungan untuk mengatasi kredit bermasalah untuk perbankan mengantisipasi kerugian seperti memberikan keringanan kepada kreditur yang tidak mampu membayar kreditnya pada waktu yang telah ditentukan atau memperpanjang jangka waktu kredit dan angsuran yang membuat perbankan akan tetap mendapatkan laba kemudian kredit macet tersebut dapat di tangani dengan baik sehingga bank mampu tetap menyalurkan kreditnya dengan lancar. Hasil penelitian ini seperti penelitian dari (Wityasari \& Pangestuti, 2014) yang menjelaskan bahwa tidak ada pengaruh NPL terhadap Profitabilitas yang dimediasi LDR.

\section{KESIMPULAN}

Dari hasil analisis data yang telah dilakukan dan pembahasan hasil penelitian, maka dapat disimpulkan terdapat pengaruh negatif dan signifikan pada variabel CAR terhadap LDR, dan variabel DPK terhadap LDR. Terdapat pengaruh positif dan signifikan pada variabel NPL terhadap LDR, tidak ada pengaruh pada variabel CAR terhadap Profitabilitas, dan variabel DPK terhadap Profitabilitas. Terdapat pengaruh negatif dan signifikan pada variabel NPL terhadap Profitabilitas, tidak ada pengaruh pada variabel LDR terhadap Profitabilitas, tidak ada pengaruh pada variabel CAR terhadap Profitabilitas melalui mediasi LDR, tidak ada pengaruh pada variabel DPK terhadap Profitabilitas melalui mediasi LDR, tidak ada pengaruh NPL terhadap Profitabilitas yang dimediasi LDR.

Pada penelitian ini masih terdapat banyak keterbatasan. Keterbatasan tersebut tentang beberapa hal diantaranya meliputi konsep, metodologi dan teknis penelitian. Bagi peneliti selanjutnya disarankan mampu memanfaatkan sampel selain Bank Umum Konvensional serta menambah variabel selain yang sudah diteliti di penelitian ini seperti NIM dan BOPO.

\section{DAFTAR PUSTAKA}

Adityantoro, Y. W. K., \& Rahardjo, S. N. (2013). Faktor - Faktor yang Memengaruhi Profitabilitas Perbankan di Indonesia. Diponegoro Journal of Accounting, 2(4), 1-12.

Agustiningrum, R. (2013). Analisis pengaruh CAR, NPL, dan LDR terhadap Profitabilitas pada Perusahaan Perbankan. E-Jurnal Manajemen Universitas Udayana, 2(8), 885-902.

Aini, N. (2013). Pengaruh CAR, NIM, LDR, NPL, BOPO, dan Kualitas Aktiva Produktif terhadap Perubahan Laba(Studi Empiris pada Perusahaan Perbankan yang Terdaftar Di Bei) Tahun 2009-2011. Dinamika Akuntansi, Keuangan Dan Perbankan, 2(1), 14-25.

Ariyanti, I., Dhiana, P. P., \& Pranaditya, A. (2017). Pengaruh CAR, NPF, NIM, BOPO, dan DPK terhadap Profitabilitas dengan FDR sebagai Variabel Intervening (Studi Kasus Perbankan Umum Syariah Tahun 2011-2014). Ekonomi Akuntansi 3(3), 1-20. 
Ivan Lisfi Alphamalana \& RA Sista Paramita. Pengaruh Capital Adequacy Rasio, Dana Pihak Ketiga, dan Non Performing Loan, terhadap Profitabilitas dengan LDR sebagai Variabel Intervening pada

Bank Umum Konvensional di Indonesia

Aulia, F., \& Prasetiono. (2016). Pengaruh CAR , FDR , NPF , dan BOPO terhadap Profitabilitas (Return On Equity) (Studi Empiris pada Bank Umum Syariah di Indonesia Periode Tahun 2009-2013 ). Diponegoro Journal of Management, 5(1), 1-10.

Ayuningrum, A. P., \& Widyarti, E. T. (2009). Analisis Pengaruh CAR, NPL, BOPO, NIM dan LDR terhadap ROA (Studi Kasus pada Bank Umum Go Public yang Listed pada Bursa Efek Indonesia Tahun 2005-2009). I-Economic, 3(1), 1-31.

Choerudin, A., Yuniatun, E., \& Kusdiasmo, B. (2016). Pengaruh Non Perfoming Loan (NPL) dan Loan To Deposit Ratio (LDR) terhadap Return On Asset (ROA) dengan Capital Adequacy Ratio (CAR) sebagai Variabel Intervening (Studi pada Bank Umum yang terdaftar di BEI Periode Tahun 2012-2015). Jurnal Ekonomi Dan Perbankan, 2(2), 28-47.

Defri. (2012). Pengaruh Capital Adequacy Ratio (CAR), Likuiditas dan Efisiensi Operasional terhadap Profitabilitas Perusahaan Perbankan yang Terdaftar di BEI. Jurnal Manajemen, 1(1), $1-18$.

Dewi, F., Arifati, R., \& Andini, R. (2016). Analysis of Effect of CAR, ROA, LDR, Company Size, NPL, and GCG to Bank Profitability (Case Study on Banking Companies Listed In Bei Period 2010-2013). Journal Of Accounting, 2(2), 2-11.

Dewi, N. T., \& Wisadha, I. G. S. (2015). Pengaruh Kualitas Aktiva Produktif, CAR, Leverage Dan LDR pada Profitabilitas Bank. E-Jurnal Akuntansi Universitas Udayana, 12(2), 295-312.

Ebenezer, O., Omar, W., \& Kamil, S. (2017). Bank Specific and Macroeconomic Determinants of Commercial Bank Profitability: Empirical Evidence from Nigeria. Journal of Finance \& Banking Studies, 6(1), 25-38.

Eng, T. (2013). Pengaruh NIM, BOPO, LDR, NPL \& CAR terhadap ROA Bank Internasional dan Bank Nasional Go Public Periode 2007 - 2011. Jurnal Dinamika Manajemen, 1(3), 153-168.

Fadjar, A., Esti, H., \& Prihatini, T. (2013). Analisis Faktor Internal Dan Eksternal Bank Yang Memengaruhi Profitabilitas Bank Umum Di Indonesia. Journal of Management and Business Review, 10(1), 63-77.

Fahmi, I. (2013). Pengantar Manajemen Keuangan. Bandung: Alfabeta.

Ferdinand, A. (2006). Metode Penelitian Manajemen (2nd ed.). Semarang: BP.

Ghozali, I. (2016). Aplikasi Analisis Multivariete dengan Program IBM SPSS 23 (8th ed.). Semarang: Badan Penerbit Undip.

Gul, S., Irshad, F., \& Zaman, K. (2011). Factors Affecting Bank Profitability in Pakistan. The Romanian Economic Journal, 14(39), 61-87.

Haritsman, E., \& Usman, B. (2017). Faktor - Faktor yang Memengaruhi Profitabilitas Bank Konvensional yang Terdaftar di Bursa Efek Indonesia. Jurnal Manajemen Bisnis, 12(1), 23-40.

Haryanto, S. (2016). Profitability Identification of National Banking Through Credit, Capital, Capital Structure, Efficiency, and Risk Level. Jurnal Dinamika Manajemen, 7(1), 11-21.

Hasan, M. B., Ahsan, A. F. M. M., Rahaman, M. A., \& Alam, M. N. (2014). Influence of Capital Structure on Firm Performance: Evidence from Bangladesh. International Journal of Business and Management, 9(5), 184-194. https://doi.org/10.5539/ijbm.v9n5p184 
Ilusmwati, N. C., \& Nuswantara, D. A. (2014). Analisis Pengaruh Kekuatan Pasar dan Struktur Efisiensi terhadap Return On Asset (Roa) Bank. Jurnal Ilmu Manajemen, 2(4), 1140-1150.

Indonesia, P. B. (2009). Peraturan Bank Indonesia NOMOR:11/25/PBI/2009.

Jha, S., \& Hui, X. (2012). A Comparison of Financial Performance of Commercial Banks: A Case Study of Nepal. African Journal of Business Management, 6(25), 7601-7611. https://doi.org/10.5897/AJBM11.3073

Kasmir. (2014). Manajemen Perbankan (Edisi Revi). Depok: Rajagrafindo Persada.

Kolapo, F., Ajayi, L., \& Aluko, O. (2016). How is Size Related to Profitability ? Post- Consolidation Evidence from Selected Banks in Nigeria. Journal of Finance \& Banking Studies, 5(4), 30-38.

Latumaerissa, J. (2014). Manajemen Bank Umum. Jakarta: Mitra Wacana Media.

Malhotra, N. (2010). Riset Pemasaran, Pendekatan Terapan. Jakarta: PT. Raja Grafindo Persada.

Masdupi, E., \& Defri. (2012). Pengaruh Capital Adequacy Ratio (CAR), Likuiditas dan Efisiensi Operasioanl terhadap Profitabilotas Perusahaan Perbankan Yang Terdaftar Di BEI. Kajian Manajemen Bisnis, 1(1), 1-18.

Masood, O., \& Ashraf, M. (2012). Bank-Specific and Macroeconomic Profitability Determinants of Islamic Banks(The case of different countries). Qualitative Research in Financial Markets Journal, 4(2), 255-268. https://doi.org/10.1108/17554171211252565

Muhidin, S. A., \& Abdurahman, M. (2007). Analisis Korelasi, Regresi dan Jalur dalam Penelitian. Bandung: Pustaka Setia.

Mumtamimah, \& Rita. (2009). Pendekatan Trade Off Theory dan Pecking Ordet Theory. Bisnis Strategi, 241-249.

Nadi, L. U. H. (2017). Analisis Pengaruh CAR , NPL dan NIM terhadap Profitabilitas Perbankan yang terdaftar di Bursa Efek Indonesia, Jurnal Ilmiah Akuntansi Universitas Pamulang 04 (2), 958-977.

Nisar, S., Susheng, W., Ahmed, J., \& Peng, K. (2015). Determinants of Bank's Profitability in Pakistan: A Latest Panel Data Evidence. International Journal of Economics, Commerce and Management, III(4), 1-16. https://doi.org/10.1515/aicue-2015-0007

Pardede, D. N., \& Pangestuti, I. R. D. (2016). Analisis Pengaruh CAR, Dana Pihak Ketiga (DPK), NIM, dan LDR terhadap Profitabilitas Perbankan dengan LDR sebagai Variabel Intervening. Ejournal-s1, 5, 1-13.

Permatasari, A. K., \& Amboningtyas, D. (2017). The Influence of LDR, DPK, and NPL on ROA through CAR as Intervening Variabel (Study on Conventional Bank Sub Sector Company 2012-2016 listed in BEI). I-Economic, 13(12), 16-17.

Pertiwi, Y. N. (2013). Pengaruh Struktur Pasar Industri Perbankan Dan Karakteristik Bank Terhadap Profitabilitas Bank Konvensional Di Indonesia Periode 2006-2011. FEB Undip Skripsi.

Pranata, A. (2015). Pengaruh Capital Adequacy Ratio, Loan to Deposit Ratio dan Ukuran Perusahaan pada Profitabilitas Bank di Bursa Efek Indonesia. E-Jurnal Akuntansi Universitas Udayana, 11(1), 235-251. 
Ivan Lisfi Alphamalana \& RA Sista Paramita. Pengaruh Capital Adequacy Rasio, Dana Pihak Ketiga, dan Non Performing Loan, terhadap Profitabilitas dengan LDR sebagai Variabel Intervening pada

Bank Umum Konvensional di Indonesia

Pratama, B. A. (2009). Analisis Faktor - Faktor yang memengaruhi Kebijakan Penyaluran Kredit Perbankan (Studi pada Bank Umum Di Indonesia Periode Tahun 2005 - 2009). Bisnis Strategi, 19(2), 1-18.

Pratiwi, L., \& Wiagustini, N. (2015). Pengaruh CAR, BOPO, NPL dan LDR Terhadap Profitabilitas. E-Jurnal Manajemen Unud, 5(4), 2137-2166.

Purnamasari, N., \& Jumono, S. (2013). Financial Performance of Banking Industry (Case Study of Foreign Bank in Indonesia in the Period of 2002Q1 - 2012Q4). Proceeding, Seminar Nasional, $S C A-3-F E B$.

Purwoko, D., \& Sudiyatno, B. (2013). Faktor-faktor yang memengaruhi Kinerja Bank (Studi empirik pada Industri Perbankan di Bursa Efek Indonesia). Journal of Business Economics and Management, 20(1), 25-39.

Putrama, A. (2017). Pengaruh Variabel Makroekonomi terhadap Profitabilitas Bank Non Devisa di indonesia periode 2012-2016. Jurnal Ilmu Manajemen, 5(2), 1-8.

Rivai, V. (2007). Bank and Financial Institution Management. Jakarta: PT. Raja Grafindo Persada.

Sabrina, F., \& Muharam, H. (2015). Analisis Pengaruh Kepemilikan Pemerintah,Kepemilikan Asing, Risiko Likuiditas dan Risiko Kredit terhadap Kinerja Keuangan Bank. Diponegoro Journal of Management, 4(1), 1-13.

Septiani, R., \& Lestari, P. vivi. (2016). Pengaruh NPL dan LDR terhadap Profitabilitas Dengan CAR sebagai Variabel Mediasi Pada PT BPR Pasarraya Kuta. E-Jurnal Manajemen Unud ISSN: 2302-8912, 5(1), 293-324.

Setiawati, M. D., \& Putra, I. W. (2015). Pengujian Trade Off Theory Pada Struktur Modal Perusahaan dalam Indeks Saham Kompas100. E-Jurnal Akuntansi Universitas Udayana, 13, 705-722.

Shidieq, H. A. (2015). Pengaruh Loan to Deposit Ratio, Non Performing Loan, Good Corporate Governance, Biaya Operasional terhadap Pendapatan Operasional, dan Capital Adequacy Ratio Terhadap Return On Assets pada Bank Devisa yang Go Public Periode 2010- 2012. EProceeding of Management, 2(1), 462-471.

Siahaan, D., \& Asandimitra, N. (2016). Pengaruh Likuiditas Dan Kualitas Aset terhadap Profitabilitas pada Bank Umum Nasional (Studi pada Bursa Efek Indonesia Periode 2010-2014). Bisnis Dan Manajemen, $9(1)$.

Sudiyatno, B., \& Suroso, J. (2010). Analisis Pengaruh Dana Pihak Ketiga, BOPO, CAR dan LDR terhadap Kinerja Keuangan pada Sektor Perbankan yang Go Public di Bursa Efek Indonesia (BEI) (Periode 2005-2008). Dinamika Keuangan Dan Perbankan, 2(2), 125-137.

Sugiyono. (2015). Metode Penelitian Kuantitatif, Kualitatif dan R\&D (22nd ed.). Bandung: Alfabeta.

Wibowo, E., \& Syaichu, M. (2013). Analisis Pengaruh Suku Bunga, Inflasi, CAR, BOPO, NPF terhadap Profitabilitas Bank Syariah. Diponegoro Journal of Management, 2(2),1-10.

Wijaya, R., \& Sihombing, P. (2012). Determinan Kinerja Profitabilitas Bank (Studi Kasus Bank yang Terdaftar di Kompas 100 - BEI Tahun 2009 - 2012). Journal of Business Strategy and Execution, 7(2), 206-235.

Wityasari, M., \& Pangestuti, I. R. D. (2014). Analisis Pengaruh Car, Dana Pihak Ketiga (DPK), NPL, 
dan LDR Terhadap Profitabilitas Perbankan Dengan LDR Sebagai Variabel Intervening, 114.Diponegoro Journal Of Management 3 (4).

Yanuardi, A., Hadiwidjojo, D., \& Sumiati. (2014). Faktor Determinan Atas Profitabilitas Perbankan yang Terdaftar di Bursa Efek Indonesia. Jurnal Akuntansi Multiparadigma, 5(2), 201-218. 